\title{
Particularities of Pregnancy and Childbirth among Adolescents' Girls in the University Teaching Hospital Yalgado Ouedraogo (UTH-YO) in Ouagadougou, Burkina Faso
}

\author{
Ouattara Adama1,2*, Ouédraogo Smaila ${ }^{1,2}$, Lankoandé Bako Natacha ${ }^{3}$, Tossou Arséne Serge², \\ Tougma Sanou Aline ${ }^{3}$, Sawadogo Yobi Alexis ${ }^{1,2}$, Millogo Traoré Francoise ${ }^{1,2}$, \\ Ouédraogo Marie Charlemagne ${ }^{1,2}$, Ouédraogo Ali1,2, Thieba Bonané Blandine ${ }^{1,2}$

\begin{abstract}
${ }^{1}$ Training and Research Unit in Health Sciences (TRU/HS), University Ouaga 1 Pr Joseph KI ZERBO, Ouagadougou, Burkina Faso ${ }^{2}$ Department of Gynecology and Obstetrics, The University Teaching Hospital Yalgado Ouedraogo of Ouagadougou (UTH-YO), Ouagadougou, Burkina Faso

${ }^{3}$ Department of Gynecology and Obstetrics, The Bogodogo University Teaching Hospital of Ouagadougou (UTH-B), Ouagadougou, Burkina Faso
\end{abstract} \\ Email: *ouattzangaadama@yahoo.fr
}

\begin{abstract}
How to cite this paper: Adama, O., Smaila, O., Natacha, L.B., Serge, T.A., Aline, T.S., Alexis, S.Y., Francoise, M.T., Charlemagne, O.M., Ali, O. and Blandine, T.B. (2018) Particularities of Pregnancy and Childbirth among Adolescents' Girls in the University Teaching Hospital Yalgado Ouedraogo (UTH-YO) in Ouagadougou, Burkina Faso. Open Journal of Obstetrics and Gynecology, 8, 1389-1398.

https://doi.org/10.4236/ojog.2018.813140
\end{abstract}

Received: October 7, 2018

Accepted: November 9, 2018

Published: November 12, 2018

Copyright ( $\odot 2018$ by authors and Scientific Research Publishing Inc. This work is licensed under the Creative Commons Attribution International License (CC BY 4.0).

http://creativecommons.org/licenses/by/4.0/

(c) (i) Open Access

\begin{abstract}
Objectives: To study the particularities of pregnancy and childbirth among adolescent girls at the University Teaching Hospital Yalgado Ouedraogo (UTH-YO) of Ouagadougou. Patients and Method: This was a comparative, descriptive and analytical cross-sectional study conducted over a 6-month period on 138 adolescent girls and 276 adults who gave birth in the obstetrics and gynecology department of the University Teaching Hospital Yalgado Ouedraogo (UTH-YO) in Ouagadougou during the study period from May 1 to October 30, 2017. The statistical analysis had used the Chi square test and the strength of the association was appreciated by the Odds Ratio (OR). The significance threshold was set at 5\%. Results: Adolescent girls had an average age of 17.04 \pm 0.72 years and $64.49 \%$ were married. The majority came from urban areas and was educated. Housewives were more represented with $73.2 \%$ and $65.94 \%$ of adolescent girls were of low socio-economic status. Concerning the level of education, 48 (34.7\%) were out of school, 57 (41.3\%) had primary level, 32 (23.2\%) secondary level and 1 (0.7\%) higher level. Primigravida was the most numerous and only 39 adolescent girls used a contraceptive method. Malaria $(\mathrm{p}=0.0247)$, preeclampsia $(\mathrm{p}=0.0008)$ and anaemia $(\mathrm{p}=0.0002)$ dominated pathologies during pregnancy in adolescent girls. The pelvis was borderline in $10.8 \%$ of adolescent girls. For newborns, teenage girls had a lower weight and an Apgar score of less than 7 higher. Perinatal mortality was
\end{abstract}


higher $(\mathrm{p}=0.0269)$. Postpartum outcomes were marked by complications with endometritis type $(\mathrm{p}=0.0315)$ and higher maternal mortality $(\mathrm{p}=$ 0.0049). Conclusion: The teenagers' pregnancy experience is marked by high maternal and perinatal morbidity and mortality. The promotion of contraception among adolescents should help to resolve this unpleasant situation.

\section{Keywords}

Teen Pregnancy, UTH-YO, Burkina Faso

\section{Introduction}

Adolescence is defined as the period of human growth and development between childhood and adulthood, that is, between the civilian ages of 10 and 19 [1]. According to the World Health Organization (WHO), pregnancy at this time is a public health problem in both developing and industrialized countries [2] [3]. Indeed, in low and middle income countries, the risk of perinatal stillbirth would be higher among children born to adolescent mothers and their children would be more vulnerable to neonatal and paediatric pathologies [4]. For some authors such as Dedecker F. [5] in Reunion Island, Iloki L.H. [6] in Congo, the risk of teenage pregnancy would vary according to the family, socio-economic, cultural and religious context. Through this study, we propose to describe the particularities of teenagers' pregnancy and childbirth at the University Teaching Hospital Yalgado Ouédraogo (UTH-YO) in the maternity ward in order to contribute to the fight against maternal mortality.

\section{Patients and Method}

It was a comparative, descriptive and analytical cross-sectional study. Data collection was conducted prospectively over a 6-month period from May 1 to October 30, 2017. The study was conducted within the Department of Gynecology and Obstetrics of University Teaching Yalgado Ouedraogo (UTH-YO) of Ouagadougou. It is a specialized department that ensures the management of gynecological and obstetrical pathologies as well as reproductive health.

The study population consisted of parturient women received in the department during the study period. To reach conclusions, we formed 2 patient groups. In the group 1, patients were recruited from patients up to 18 years of age who delivered in the department and in the group 2, patients were recruited from over 18 years of age who delivered during the same period. The sample size was determined by Schwartz's formula: $N=\frac{\alpha 2 \times p \times q}{i 2}$. During the study period we recorded 138 teenage parturient women. Matching was done on the basis of the number of previous deliveries with a ratio of 1 teenager to 2 adults. The voluntary consent of the patients was obtained prior to their inclusion.

All the variables studied were collected during the interview with the patients, 
through the patients' medical records and finally using the prenatal consultation notebooks of the parturient. The socio-economic level was evaluated according to a score obtained from the sum of the quotation of the different elements of the professional activity, the source, the place of residence, the presence of running water, electricity, the type of toilet and means of travel. According to the total score obtained, the socio-economic level was judged as follows: 5 to 10: "low" 1 to 14: "average" 15 to 17 : "high".

The purpose of the study was explained to the patients and their verbal consent was obtained prior to data collection. Data processing and analysis were carried out using EPI INFO software version 7, Word 2013 and Excel 2013. The statistical analysis had used the Chi square test and the strength of the association was appreciated by the Odds Ratio (OR). The significance threshold was set at $5 \%$.

\section{Results}

\subsection{Profile of Teenage Girls}

The average age of adolescent girls was $17.4 \pm 0.72$ years with extremes of 15 and 18 years. Adolescent girls at least 18 years of age were the most represented with a frequency of $54.3 \%$.

A total of 89 patients (64.5\%) were already married, 31 (22.5\%) were cohabiting and $18(13 \%)$ were single. Depending on the origin, 90 or $65.2 \%$ lived in urban areas, 44 or $31.8 \%$ lived in rural areas and 4 or $2.9 \%$ lived in semi-urban areas.

Concerning the level of education, 48 (34.7\%) were out of school, 57 (41.3\%) had primary level, $32(23.2 \%)$ secondary level and $1(0.7 \%)$ higher level. They were housewives in 101 cases (73.2\%), pupils in 24 cases (17.4\%), informal sector in 7 cases $(5.07 \%)$, farmers in 5 cases (3.6\%) and civil servants in 1 case (0.7\%).

They were first in 135 cases (97.8\%) and second in 3 cases (2.1\%) and had not already used a modern method of contraception in 4 cases (2.9\%). 99 pregnant women had not used any contraceptive methods. The current pregnancy was desired in only $13.7 \%$ of cases.

\subsection{Study of the Associated Factors}

\section{- Socio-demographic factors}

The analysis of socio-demographic factors associated with teen pregnancy has been presented in Table 1.

There was a statistically significant difference between the two groups for the variables age, socio-economic level, education level, marital status.

\section{- Pathologies during pregnancy}

The study of factors associated with the occurrence of pathologies during pregnancy has been presented in Table 2 .

Group 1 patients are 2.1 times more likely to develop malaria than the control.

\section{- Characteristics of childbirth}


Table 1. Distribution of socio-demographic factors associated with teenage pregnancy.

\begin{tabular}{lccc}
\hline $\begin{array}{c}\text { Socio-Demographic } \\
\text { Characteristics }\end{array}$ & $\begin{array}{c}\text { Group 1 } \\
\text { n (\%) }\end{array}$ & $\begin{array}{c}\text { Group 2 } \\
\text { n (\%) }\end{array}$ & p value \\
\hline Average age (years) & $17.4 \pm 0.7$ & $27.7 \pm 6.2$ & $<0.001$ \\
Marital Status & & & \\
- Single & $18(13)$ & $12(4.3)$ & $<0.001$ \\
- Concubines & $31(22.3)$ & $12(26.1)$ & \\
- Married & $89(64.4)$ & & \\
Level of education & & $100(36.3)$ & \\
- Not schooled & $57(41.3)$ & $59(21.4)$ & $<0.001$ \\
- Primary & $48(34.7)$ & $97(35.1)$ & \\
- Secondary & $32(23.3)$ & $20(7.2)$ & \\
- Superior & $1(0,7)$ & & \\
Socio-economical level & & $148(53.6)$ & \\
- Low & $91(65.9)$ & $108(39.2)$ & 0.0032 \\
- Middle & $45(32.7)$ & $20(7.2)$ & \\
- High & $2(1.4)$ & & \\
\hline
\end{tabular}

Table 2. Distribution of patients in the 2 groups according to the risk of pathologies occurring during pregnancy.

\begin{tabular}{ccccc}
\hline Pathologies & $\begin{array}{c}\text { Group I } \\
\mathbf{n}(\%)\end{array}$ & $\begin{array}{c}\text { Group II } \\
\mathbf{n}(\%)\end{array}$ & OR [IC à 95\%] & P value \\
\hline Malaria & $23(16.6)$ & $24(8.7)$ & $2.1[1.13-3.87]$ & 0.0247 \\
Anemia & $12(8.6)$ & $3(1)$ & $8.6[2.40-31.25]$ & 0.0002 \\
Urinary Infection & $3(2.1)$ & $1(0)$ & $6.11[0.62-59.3]$ & NS \\
Pneumopathy & $1(0.7)$ & $3(1)$ & $0.66[0.06-6.49]$ & NS \\
Pre Eclampsia & $16(11.6)$ & $8(2.9)$ & $4.39[1.83-10.54]$ & 0.0008 \\
Eclampsia & $9(6.5)$ & $5(1.8)$ & $3.78[1.24-11.51]$ & 0.0270 \\
Placenta previa & $1(0.7)$ & $5(1.8)$ & $0.66[0.06-6.44]$ & NS \\
HRP & $1(0.7)$ & $9(3.2)$ & $0.21[0.02-1.72]$ & NS \\
Exceeding term & $3(2.1)$ & $8(2.9)$ & $0.74[0.19-2.85]$ & NS \\
Anamnios & $0(0.00)$ & $1(0.3)$ & & NS \\
\hline
\end{tabular}

NS $=$ Not significant

The analysis of delivery characteristics in the 2 groups was presented in Table 3.

There was a statistically significant difference between the two groups for pelvic quality variables $(\mathrm{p}=0.0001)$, amniotic fluid appearance $(\mathrm{p}=0.0002)$, episiotomy practice $(\mathrm{p}=0.0000)$ and mean duration of labor $(\mathrm{p}=0.0031)$.

\section{- Newborn features}

The analysis of newborn characteristics in the 2 groups was represented in Table 4.

The average birth weight of newborns in Group 1 patients was 2617.8 grams compared to 2812.4 grams in Group 2 ( $\mathrm{p}=\mathrm{NS}$ ).

There was a statistically significant difference between the two groups for 
Table 3. Distribution of patients in the 2 groups according to delivery characteristics.

\begin{tabular}{lccc}
\hline $\begin{array}{c}\text { Characteristics of } \\
\text { childbirth }\end{array}$ & $\begin{array}{c}\text { Group 1 } \\
\mathbf{n}(\%)\end{array}$ & $\begin{array}{c}\text { Group 2 } \\
\mathbf{n}(\%)\end{array}$ & p \\
\hline $\begin{array}{l}\text { Basin } \\
\text { - Shrinked }\end{array}$ & $15(10.8)$ & $5(1.8)$ & 0.0001 \\
- Practicable & $123(89.2)$ & $271(98.2)$ & \\
Amniotic Liquid & $110(79.8)$ & $257(93.2)$ & 0.0002 \\
- Clear & $28(20.2)$ & $19(6.8)$ & \\
- Colored & $124(89.8)$ & $239(86.6)$ & NS \\
$\begin{array}{l}\text { Presentation } \\
\text { - Acme }\end{array}$ & $13(9.4)$ & $31(11.3)$ & \\
- breech & $1(0.8)$ & $6(2.1)$ & \\
- Other & $50(72.5)$ & $50(36.2)$ & 0.0000 \\
Episiotomy & $19(27.5)$ & $88(63.8)$ & \\
- Yes No & $1(1.4)$ & $0(0.00)$ & $\mathrm{NS}$ \\
Tearing of the cervix & $0(0.00)$ & $4(2.8)$ & $\mathrm{NS}$ \\
Hemorrhage of delivery & $1(0.7)$ & $0(0.00)$ & $\mathrm{NS}$ \\
Uterine rupture & $2 \mathrm{~h} 28 \mathrm{~min}$ & $2 \mathrm{~h} 12 \mathrm{~min}$ & 0.0031 \\
\hline Average duration of delivery & &
\end{tabular}

NS $=$ Not significant

Table 4. Distribution of patients in the 2 groups according to the characteristics of newborns.

\begin{tabular}{cccc}
\hline $\begin{array}{c}\text { Characteristics of } \\
\text { The new born }\end{array}$ & $\begin{array}{c}\text { Group 1 } \\
\mathbf{n}(\%)\end{array}$ & $\begin{array}{c}\text { Group 2 } \\
\mathbf{n}(\%)\end{array}$ & $\mathbf{p}$ \\
\hline $\begin{array}{c}\text { Birth weight } \\
-<2500 \mathrm{~g}\end{array}$ & $84(60.8)$ & $62(22.4)$ & \\
- from 2500 to $4000 \mathrm{~g}$ & $54(39.2)$ & $205(74.4)$ & 0.0000 \\
$-\geq 4000 \mathrm{~g}$ & $0(0.00)$ & $9(3,2)$ & \\
Apgar at the 5th minute & & & \\
$-<7$ & $45(32.7)$ & $42(15.2)$ & 0.0000 \\
$-\quad 7$ & $93(67.3)$ & $234(84.8)$ & \\
Malformation & & & \\
$-\quad$ yes & $0(0.00)$ & $3(1.1)$ & \\
- No & $138(100)$ & $273(98.9)$ & \\
Perinatal mortality & & & \\
- yes & $16(11.6)$ & $14(5.1)$ & 0.0269 \\
- No & $122(88.4)$ & $262(94.9)$ & \\
\hline
\end{tabular}

NS $=$ Not Significant

birth weight variables $(\mathrm{p}=0.000)$, 5th minute Apgar $(\mathrm{p}=0.0000)$, perinatal mortality $(p=0.0269)$.

\section{- The suites of diapers}

The analysis of complications in post-partum in the 2 groups was presented in Table 5.

The average length of stay in Group 1 (3.09 days) was longer than Group 2 with 2.82 days with no significant difference. 
Table 5. Distribution of patients in the 2 groups according to complications following childbirth.

\begin{tabular}{ccccc}
\hline $\begin{array}{c}\text { Complications } \\
\text { Following Childbirth }\end{array}$ & $\begin{array}{c}\text { Group 1 } \\
\mathbf{n}(\%)\end{array}$ & $\begin{array}{c}\text { Group 2 } \\
\text { N (\%) }\end{array}$ & $\begin{array}{c}\text { OR } \\
\text { [IC à 95\%] }\end{array}$ & p \\
\hline Endometritis & $7(5)$ & $3(1)$ & 4.86 & 0.0315 \\
$\begin{array}{c}\text { Suppuration of the } \\
\text { Episiotomy wound }\end{array}$ & $1(0.7)$ & $0(0.00)$ & - & NS \\
Release of episiotomy wires & $1(0.7)$ & $0(0.00)$ & $-19.10]$ & NS \\
Anemia & $23(16.6)$ & $7(2.5)$ & $\begin{array}{c}7.68 \\
{[3.20-18.41]}\end{array}$ & 0.0000 \\
$\begin{array}{c}\text { Suppuration of the surgical } \\
\text { wound }\end{array}$ & $5(3.6)$ & $4(1.4)$ & $\begin{array}{c}2.55 \\
{[0.67-9.67]}\end{array}$ & NS \\
Maternal mortality & $12(8.7)$ & $6(2.1)$ & $\begin{array}{c}4.28 \\
{[1.58-11.67]}\end{array}$ & 0.0049 \\
\hline
\end{tabular}

Maternal mortality is 4 times higher in group 1 than in group 2. Also anemia is 8 times more frequent in group 1 compared to group 2.

\section{Discussion}

\subsection{Limitations of the Study}

Our study could have been affected by some limitations:

- The selection bias: the age of the patients was obtained by the interrogation and by the exploitation of the notebooks. The confrontation of the latter with that recorded in the national identity card has not been carried out; this could be at the origin of a bias.

- Information bias: part of our survey record included past information (personal and family history) and patients had to use their memory for answers.

\subsection{Description of Teenage Girls}

The mean age of Group 1 patients was $17.4 \pm 0.7$ years and that of Group 2 patients was $27.7 \pm 6.2$ years. These results are similar to those of Hamada [7] in Morocco which found an average age of 17.9 years. However, our results differ from those of Iloki [6] in Congo Brazzaville who found an average age of 14 and 20 years for group 1 and group 2 patients respectively. This could be explained by the fact that the lower age limit among adolescents in our study was 15 years compared to 10 years in Iloki's study [6].

Among the patients in group 1, 22.4\% were single, 13\% were concubines and $64.5 \%$ were married compared to group 2, $4.3 \%$ were single, $26.1 \%$ were concubines and $69.6 \%$ were married. This difference was statistically significant ( $\mathrm{p}=$ 0.0000). Hamada [7] in Morocco found $90.3 \%$ of married adolescent girls. However Odile [8] in Guyana noted 74.12\% of unmarried adolescents.

The high frequency of married adolescent girls in our series could be explained by the fact that early marriages are still a topical issue. In Burkina Faso, 
more than a third of young women aged 15 to 19 are married [9]. The same higher frequency in Morocco could be explained by the fact that in Islamic societies girls are married very early, especially in rural areas, to preserve their virginity [10].

In group $1,58.7 \%$ of patients were enrolled in school compared to $63.7 \%$ in group 2 ( $\mathrm{p}=0.0000)$. Harouna [11] in Mali also found an adult enrolment rate $(62 \%)$ significantly higher than that of adolescent girls $(40 \%) \mathrm{p}=0.0012$. These high rates in our series would be due to the urban situation of our study framework since at the national level it is $45 \%$ despite the efforts made by our authorities.

Most publications recognize the need and value of educating young women. In fact, those who benefit from them postpone their marriage or their maternity. Education also contributes to children's health and facilitates the use of information and services. Moreover, early motherhood and early marriage have a heavy impact on the educational level of adolescent girls. Many teenage girls are dropping out or failing school because of pregnancy or marriage and come to increase the number of "housewives" [12] [13] [14].

\subsection{Pathologies during Pregnancy}

In our series, malaria, anemia, pre-eclampsia and eclampsia are significantly more frequent in group 1 than in group 2 according to the literature [6] [10] [11].

Thus, the risk of group 1 patients contracting malaria was 2.1 times higher than that of group 2 patients. These results remind us that malaria is still relevant today. Indeed, 25 million pregnant women, $20 \%$ of whom are primiparous, face the consequences of malaria in sub-Saharan Africa, despite WHO recommendations based on the administration of intermittent preventive treatment (IPT) and the use of long-lasting insecticide-treated nets (LLINs) for prevention. Malaria causes fetal suffering because of the progressive anaemia it causes in the mother, fetal hypotrophy, fetal death in utero, abortion in early pregnancy and prematurity at the end of pregnancy [11].

Group 1 patients were 8.6 times more likely to develop anemia than Group 2 patients. Adolescent anaemia may be due, on the one hand, to competition between the metabolic demands of the growing adolescent's body and the nutritional needs of her fetus and, on the other hand, to the lack of iron and folic acid supplementation resulting from low attendance at antenatal clinics [10].

The risk of pre-eclampsia in our series for group 1 patients was 4.39 times greater than for group 2 patients. Several factors determine the population at high risk of developing vascular-renal syndromes [1]:

- Young age: most studies confirm that pregnant hypertension is a disease of very young women.

- Primiparity the relationship between pregnant hypertension and primiparity is explained by three factors: the inadequacy of the mother's body to the 
upheavals of pregnancy in the case of a young primiparous, renal hemodynamic disorder, and the fact that the mother's body is not adapted to the changes in her pregnancy.

\subsection{Characteristics of Childbirth}

The basin was limited in $10.8 \%$ and $1.8 \%$ respectively in group 1 and 2 with $\mathrm{p}=$ 0.0001 . Our results are similar to those of Mehest [14] who found $2.8 \%$ of pelvis narrowed in adolescents and Genset [4] reported $8.33 \%$. The role of age in the incidence of narrowed pelvis has been evoked by several authors who have defined an age limit situated around 18 years of age as the responsible of narrowed pelvis and beyond which the pelvis is sufficiently developed although immature to allow the low birth of a newborn of normal weight [14] [15] [16].

Amniotic fluid was tinted in $20.2 \%$ of cases for group 1 versus $6.8 \%$ of cases for group 2 with a statistically significant difference $p=0.0002$. These results are similar to those of Iloki [6] in Congo Brazzaville and Harouna [11] in Mali, which respectively found tinted amniotic fluid in $31 \%$ of adolescents compared to $15.1 \%$ in the control group and $67 \%$ in adolescents compared to $33 \%$ in adults. This higher rate of group 1 patients with tinted amniotic fluid could be explained by the prolonged duration of childbirth due to the primiparity but also to the immaturity of the bony pelvis with the consequence of acute fetal suffering (AFP) which translates into several signs including the tinge of the amniotic fluid. The average working time was 149.45 minutes in group 1 versus 132.61 minutes in group 2. Hamada [7] in Morocco achieved the same results with an active labour phase duration of 2 hours 16 minutes or 136 minutes for adolescent girls versus 2 hours 4 minutes or 124 minutes for controls, with no statistically significant difference. The primiparity, immaturity of the pelvis but also the indocility of the adolescent could explain this state of affairs.

\subsection{Characteristics of Newborns}

The average birth weight of newborns in Group 1 patients was 2617.8 grams compared to 2812.4 grams in Group 2. Authors such as Hamada [7] in Morocco, Iloki [6] in Congo Brazzaville found that the birth weight of adolescent girls' newborns was significantly lower than that of the control group. Newborns under 2500 g represented $60.8 \%$ in group 1 compared to $22.4 \%$ in group 2 with a statistically significant difference $p=0.0000$. Our results are similar to those of Harouna [11] in Mali and Iloki [6] in Congo Brazzaville who also found a percentage of low birth weight (less than $2500 \mathrm{~g}$ ) among adolescents higher than that of the control group with respectively $30 \%$ against $11.5 \%$ and $22.1 \%$ against $15.7 \%$. Indeed, many authors agree that in Africa, low birth weight is a major characteristic of children born to teenage mothers [6] [12] [14]. Several studies attribute this risk of low birth weight to factors that may be associated with young maternal age: anaemia, maternal physical condition, premature delivery, pathologies associated with pregnancy, insufficient maternal weight gain, ma- 
ternal nutritional status and poor quality of pregnancy follow-up [7]. When the mother is less than 15 years old, the birth weight frequency of less than $2500 \mathrm{~g}$ would be multiplied by two compared to the general population. Low birth weight babies, whether premature or term, contribute not only to neonatal mortality but also to early childhood morbidity [8].

In our series, $11.5 \%$ of infants in Group 1 were stillborn compared to $5 \%$ in Group 2 ( $\mathrm{p}=0.0269)$. Konaté [10] in Mali found $4 \%$ of stillborn teenage mothers and Iloki [6] in Congo Brazzaville found higher mortality among newborn teenage girls (53\%) compared to the control group 14\%. Indeed, low birth weight, neonatal suffering and primiparity especially in adolescents are intriguing factors of high risk of perinatal mortality [8]. This leads some authors to say that in low- and middle-income countries, stillbirths and neonatal deaths are twice as common among children born to mothers under the age of 20 as among those born to mothers aged 20 to 29 . The younger the mother, the greater the risk to the child. Children of teenage mothers are more likely to have low birth weight, with a risk of long-term complications [4] [13] [14] [15] [16].

\subsection{Diapers' Suites}

The proportion of group 1 patients who developed endometritis and anemia is significantly higher than in group 2 with a risk for group 1 patients to have anemia 7.68 times higher than in group 2. The risk of endometritis in group 1 patients was 4.86 times greater than in group 2. Some authors such as Hamada [7] in Morocco did not find any significant difference between the two groups with regard to diaper sequences. The average length of stay in Group 1 (3.09 days) was longer than Group 2 with 2.82 days with no significant difference. Maternal mortality in group 1 (7.97\%) was 4.28 times higher than in group 2 (2.17\%). Niang [12] in Senegal found no significant difference between the adolescent $(3.6 \%)$ and adult (1.3\%) mortality rates.

\section{Conclusion}

The experience of pregnancy, childbirth and the aftermath of childbirth in adolescents at the UTH-YO are dominated by the preponderance of elements of poor prognosis. The need to reposition family planning by developing a specific strategy for adolescent girls should contribute to the fight against maternal mortality.

\section{Conflicts of Interest}

The authors declare no conflicts of interest regarding the publication of this paper.

\section{References}

[1] Babatundi, O. (2013) State of the World Population in 2013: Adolescent Pregnancy in West and Central Africa. UNFPA, New York. 
[2] World Health Organization (2014) Adolescent Pregnancy. Fact Sheet No. 364.

[3] World Health Organization (2008) Early Marriage among Adolescents and Young Women. Secretariat Report.

[4] Genest, L., Decroix, H., Rotteu, D. and Simmat-Durand, L. (2014) Early Motherhood: Socio-Demographic Profile of 220 Teenage Mothers in Seine-Saint-Denis. Journal de Gynécologie Obstétrique et Biologie de la Reproduction, 43, 351-360. https://doi.org/10.1016/j.jgyn.2013.03.009

[5] Dedecker, F., De Bailliencourt, D., Barau, G., Fortier, D., Robillard, P.Y., Roge-Wolter, M.M., Djemili, S. and Gerardin, P. (2005) Study of Obstetric Risk Factors in the Follow-Up of 365 Teenage Primiparous Pregnancies on Reunion Island. Journal de Gynécologie Obstétrique et Biologie de la Reproduction, 34, 694-701. https://doi.org/10.1016/S0368-2315(05)82903-5

[6] Iloki, L.H., Koubaka, R. and Itoua, C. (2004) Pregnancy and Childbirth among Adolescents in Congo about 276 Cases at Brazzaville University Hospital. Journal de Gynécologie Obstétrique et Biologie de la Reproduction, 33, 112-116.

[7] Hamada, H., Zaki, A., Nejjar, H., Filali, A., Chraibi, C. and Bezad, R. (2004) Teen Pregnancy and Childbirth: Characteristics and Profile about 311 Cases. Journal de Gynécologie Obstétrique et Biologie de la Reproduction, 33, 609-614.

[8] Odile, M. (2000) Pregnancy and Childbirth among Adolescents under 16 in Guyana. Master Thesis, Henri Poincaré University, Nancy, 86 p.

[9] Guiella, G. (2004) Sexual and Reproductive Health of Young People in Burkina Faso: An Overview. Occasional Report, New York.

[10] Konate, B. (2009) Gyneco-Obstetrical Emergencies in Adolescent Girls at the Referral Health Centre in Commune II of the Bamako District. Master Thesis, University of Bamako, Bamako, 96 p.

[11] Harouna, D., Diallo, G., Tall, E., Sissoko, E. and Dollo, A. (2011) Adolescent Delivery at the Referral Health Centre in Commune $\mathrm{V}$ of Bamako (Mali). Thesis Med. GFATM Bamako, 59 p.

[12] Niang, M., Aidibe, I., Ngom, P.M., Thiam, M., Diouf, A.A., Ndiaye, D., Gueye, M., Guisse, B., Balde, Y., Cisse, C.T. and Moreau, J.C. (2013) Pregnancy and childbirth among Adolescent Girls in Senegal: About 302 Cases Collected at the Ninefécha Hospital. OAG Journal, 14, 30-35.

[13] Soula, O., Carles, G., El Guindi, W. and Montoya, N. (2006) Pregnancy and Childbirth among Adolescents under 15: Studies on 181 Cases in French Guiana. Journal de Gynécologie Obstétrique et Biologie de la Reproduction, 35, 53-61. https://doi.org/10.1016/S0368-2315(06)76372-4

[14] Mehest, K. and Marlene, L. (2013) Human Capital Consequences of Teenage Pregnancy in South Africa. Population Office Reference.

[15] Guiot, O., Foucau, T., Janky, E. and Kadhel, P. (2013) Pregnancies in Minors in Guadeloupe: New Inventory. Journal de Gynécologie Obstétrique et Biologie de la Reproduction, 42, 372-382. https://doi.org/10.1016/j.jgyn.2013.02.007

[16] Ba, M.G., Sangaré, M., Moreira, P. and Diadiou, F. (1999) Practical Knowledge and Perspective on Contraception among Adolescents. Black African Medical Journal, 46, 300-302. 